\title{
Percepções de enfermeiros da atenção primária no atendimento às mulheres vítimas de violência sexual
}

\begin{abstract}
RESUMO | Objetivo: analisar a percepção dos enfermeiros sobre o atendimento às mulheres vítimas de violência sexual na atenção primária. Método: estudo de natureza descritivo-exploratório com abordagem qualitativa, desenvolvido com sete enfermeiros de uma unidade básica de saúde do Distrito Federal. Os dados foram coletados a partir de entrevistas e analisadas mediante análise de conteúdo. A pesquisa foi aprovada pelo Comitê de Ética em Pesquisa UNIP sob o parecer $n^{\circ} 3.425 .175$. Resultados: a empatia foi um sentimento presente nos enfermeiros, bem como a frustação; a falta de conhecimento específico sobre a temática e a dificuldade na identificação dos casos de violência sexual também estiveram presentes e podem resultar na subnotificação dos casos na atenção primária. Conclusão: torna-se necessário uma abordagem indireta do enfermeiro às mulheres através de questionamentos sobre a ocorrência de violência sexual, bem como a incorporação da temática na graduação e a realização de educação permanente aos profissionais.
\end{abstract}

Palavras-chaves: Violência contra a mulher; Atenção primária à saúde; Enfermagem.

ABSTRACT | Objective: to analyze nurses' perception of the care provided to women victims of sexual violence in primary care. Method: this is a descriptive and exploratory study with a qualitative approach, developed with seven nurses from a basic health unit in the Federal District. Data were collected from interviews and analyzed using content analysis. The UNIP Research Ethics Committee under opinion $n^{\circ}$ 3.425.175 approved the research. Results: empathy was a feeling present in nurses, as well as frustration; the lack of specific knowledge on the subject and the difficulty in identifying cases of sexual violence were also present and may result in underreporting of cases in primary care. Conclusion: it is necessary to take an indirect approach from the nurse to women through questions about the occurrence of sexual violence, as well as the incorporation of the theme in graduation and the realization of permanent education for professionals.

Keywords: Violence against women; Primary health care; Nursing.

RESUMEN | Objetivo: analizar la percepción de las enfermeras sobre la atención brindada a las mujeres víctimas de violencia sexual en atención primaria. Método: estudio descriptivo-exploratorio con enfoque cualitativo, desarrollado con siete enfermeras de una unidad básica de salud en el Distrito Federal. Los datos se recopilaron de entrevistas y se analizaron mediante análisis de contenido. La investigación fue aprobada por el Comité de Ética en Investigación UNIP bajo la opinión n 3.425.175. Resultados: la empatía era un sentimiento presente en las enfermeras, así como la frustración; la falta de conocimiento específico sobre el tema y la dificultad para identificar casos de violencia sexual también estuvieron presentes y pueden dar como resultado un subregistro de casos en atención primaria. Conclusión: es necesario adoptar un enfoque indirecto de la enfermera a las mujeres a través de preguntas sobre la ocurrencia de violencia sexual, así como la incorporación del tema en la graduación y la realización de educación permanente para profesionales. Descriptores: Violencia contra la mujer; Atención primaria de salud; Enfermería.

Juliana Arrais Mota

Enfermeira. Graduada pela Universidade

Paulista (UNIP), Campus Brasília-DF, Brasil.

\section{Ricardo Saraiva Aguiar}

Enfermeiro. Professor Assistente. Curso de Graduação em Enfermagem, Universidade Paulista (UNIP), Campus Brasília-DF, Brasil.

Recebido em: 29/11/2019

Aprovado em: 26/01/2020

INTRODUÇÃO

$\Lambda$ violência contra as mulheres é considerada uma violação dos direitos humanos e um problema de saúde pública devido as repercussões na saúde física, psíquica e social. Ela está enraizada na desigualdade de gênero e constitui um impedimento ao desenvolvimento social, pois mundialmente cerca de 30\% das mulheres já vivenciaram tal situação, sendo as meninas jovens, as mulheres pertencentes a determinadas etnias, as transexuais e/ou as com deficiência o público que enfrenta maior risco de exposição às diferentes formas de violência. ${ }^{1-2}$

O termo violência contra a mulher traduz as diversas formas de violência, incluindo a realizada por parceiros íntimos, seja física, sexual ou psicológica, bem como outros tipos de violência como a mutilação, assassinatos e tráfico de mulheres. ${ }^{3}$

Como subsídio para este enfrentamento, foi implementada em âmbito nacional a Política Nacional de Enfrentamento à Violência contra as Mulheres. Esta política está organizada em eixos estruturantes capazes de estabelecer conceitos, princípios, diretrizes e ações que minimizem a ocorrência de episódios de violência contra às mulheres e garanta a oferta de uma assistência integral, humanizada e com qualidade. ${ }^{1}$

No campo da saúde, os profissionais devem voltar sua assistência para a integralidade e ir além das questões físicas ou problemas orgânicos de modo a adotar posturas sensíveis e acolhedoras com a vítima para possibilitar o manejo e seguimento adequado, além da redução de casos..$^{2-4}$

O profissional, em particular o enfer- 
meiro, deve ser capaz de atuar na tentativa da resolução do problema e contribuir para a redução do ciclo da violência através da atuação e articulação da rede de serviços disponíveis visando maior fluidez e eficácia no atendimento. Entretanto, a violência sexual é pouco identificada e é subnotificada nos serviços de atenção primária à saúde (APS), mascarando a gravidade da situação. ${ }^{4}$

Assim, este estudo se faz necessário uma vez que poderá demonstrar quais as possibilidades e limitações na assistência à saúde, visando a qualidade do atendimento às mulheres. ${ }^{2,4}$ Diante disso, destaca-se a questão que norteou a presente proposta investigativa: qual a percepção dos enfermeiros da atenção primária sobre a assistência à saúde de mulheres vítimas de violência sexual?

Portanto, este estudo tem o objetivo de analisar a percepção dos enfermeiros sobre o atendimento às mulheres vítimas de violência sexual na atenção primária.

\section{MÉTODO}

Trata-se de um estudo de natureza descritivo-exploratório com abordagem qualitativa, desenvolvido em uma unidade básica de saúde (UBS) do Distrito Federal, Brasil.

Participaram deste estudo enfermeiros que atenderam ao seguinte critério de inclusão: atuação nas equipes de Estratégia de Saúde da Família (ESF) da UBS por no mínimo 6 meses. A determinação do número de participantes obedeceu ao critério de saturação das informações. Ao final da coleta de dados, contou-se com a participação de 7 enfermeiros.

A coleta de dados ocorreu entre os meses de julho e setembro de 2019, em dois momentos. No primeiro, foi possível conhecer o funcionamento da instituição e obter as informações necessárias para o recrutamento e início da coleta de dados. No segundo momento, aplicou-se um roteiro de entrevista semiestruturado com cada participante, dividido em duas partes: a primeira com os dados de identi- ficação dos enfermeiros e a segunda com as perguntas norteadoras.

O tempo médio das entrevistas foi de 45 minutos e os participantes estavam no início ou final de expediente. As perguntas norteadoras foram: Atender mulheres que vivenciaram a violência sexual pode despertar algum sentimento? Caso sim, quais? e Explicite como que é para você atuar nesse tipo de atendimento?

Visando a privacidade dos enfermeiros, as entrevistas ocorreram de forma individual, em uma sala privativa da instituição e em horário combinado antecipadamente. Os discursos foram capturados por um gravador de áudio e com a concessão dos enfermeiros, por meio da assinatura do Termo de Consentimento Livre e Esclarecido.

As falas foram transcritas e analisadas por meio da proposta de análise de conteúdo, a qual se organiza nas seguintes fases: pré-análise, exploração do material, tratamento dos resultados, inferência e interpretação. ${ }^{5}$

Na pré-análise, houve a leitura flutuante, seguida da constituição do corpus, de acordo com o objetivo proposto. Para a exploração do material, realizou-se a codificação por meio das palavras ou frases semelhantes nos discursos. Na fase de tratamento dos resultados e da interpretação, foi possível agrupar os fragmentos das narrativas em relevo com o intuito de visualizar as informações obtidas com plenitude, bem como abranger as inferências previstas.

Atendendo a garantia do sigilo das identidades dos participantes, para a apresentação dos relatos utilizou-se a letra " $\mathrm{E}$ " seguida pelo número arábico correspondente à ordem na entrevista (E1 a E7).

Os aspectos éticos foram respeitados, conforme exigência da Resolução $n^{\circ}$ 466/2012, do Conselho Nacional de Saúde, que trata da pesquisa em seres humanos. O projeto foi submetido e aprovado pelo Comitê de Ética em Pesquisa da Universidade Paulista sob o parecer $n^{\circ} 3.425 .175$ (CAAE 15152819.0.0000.5512), de 28 de junho de 2019.

\section{RESULTADOS E DISCUSSÃO}

Foram entrevistados 7 enfermeiros que desenvolvem suas atividades profissionais em uma UBS no Distrito Federal, sendo $85,7 \%$ do sexo feminino e com média de idade de 50 anos. Em relação ao nível de instrução, 28,6\% tinham somente a graduação em Enfermagem; 57,1\% pós-graduação latu sensu; e 14,3\% pós-graduação stricto sensu. Quanto ao tempo de trabalho na Enfermagem, 71,4\% atuam na profissão há mais de 10 anos. Sobre o tempo de trabalho na UBS, $85,7 \%$ dos enfermeiros trabalham há mais de 3 anos e 14,3\% de 1 a 2 anos. Em relação a jornada de trabalho dos profissionais, 85,7\% apresentam jornada de trabalho de até 40 horas semanais e 14,3\% superior a 40 horas semanais.

Considerada um problema de saúde global, que atinge mulheres em diferentes idades e realidades, a violência contra mulher pode ocorrer de diversas formas, incluindo a violência física, psíquica e sexual, na maioria das vezes, motivados pela desigualdade de gênero, onde o masculino tem maior poder sobre o feminino. Diante dessa realidade, cabe aos serviços de saúde identificar os casos de violência e prestar assistência, atendendo as vítimas em suas necessidades especificas. ${ }^{3}$

Diante disso, os resultados obtidos por meio das entrevistas indicaram diversos sentimentos que são despertados nos enfermeiros ao atenderem mulheres que vivenciaram um episódio de violência sexual, sendo que a empatia foi o principal deles, como observa-se:

A empatia né! Mesmo que de forma profissional ela é inevitável. (E1)

Eu vejo mais essa questão da frustação. É como se fosse uma linha muito tênue, pois você fica no dilema: ou você presta atenção na parte física ou na parte psicológica. Até que ponto isso se mistura? Se houve mesmo agressão da parte do parceiro? Ou a mulher se sujeita a deixar isso 
acontecer? [...] (E2)

Um sentimento de frustação, tristeza e inconformidade com tamanha crueldade. (E3)

Desperta a empatia, desperta a dor, a piedade, pois elas passam por um sofrimento muito grande. Então, eu acho que desperta isso aí e muitas vezes a revolta. (E4)

Sentimento de pena. O maior sentimento que tive por ela foi de pena né, mas a gente não pode nem pensar nisso, pois tem que enfrentar o atendimento e tem que dar uma de durona mesmo. (E5)

Sentimento de querer ajudar né! É uma coisa muito complicada né! A pessoa ali vai ficar com o trauma por um bom tempo, então o sentimento é de querer ajudar mesmo, de querer auxiliar, aconselhar e tentar ajudar o máximo que a gente puder para poder resolver o problema. (E6)

Sentimento de tristeza, medo e desconfiança. (E7)

Diante dos depoimentos, a existência da empatia por partes dos enfermeiros pode possibilitar um cuidado sensível e acolhedor atendendo a vítima de forma equânime. ${ }^{6}$ Já a ausência dela pelos profissionais durante o atendimento pode resultar no afastamento da mulher dos serviços de saúde. ${ }^{7}$ A empatia é definida como a capacidade de colocar-se no lugar do outro como forma de possibilitar a compreensão do que o outro está vivenciando/ sentindo com o objetivo de assistir as suas necessidades de forma eficiente. ${ }^{6}$

Assim, este sentimento associado à sensibilidade, à escuta qualificada e a calma deve fazer parte do cotidiano do enfermeiro que atende mulheres vítimas de violência sexual com a finalidade de identificar os riscos e as vulnerabilidades das mulheres, visando o acolhimento e a integralidade no cuidado. ${ }^{6}$

Entretanto, a existência do sentimento de frustação por parte dos profissionais é, muitas vezes, desgastante e pode resultar em uma sensação de impotência, o que pode causar outros sentimentos como intolerância e o descaso diante da violência contra a mulher. Dessa forma, o treinamento e a disseminação de informações acerca do assunto e a supervisão de profissionais de saúde mental aos enfermeiros da atenção primária pode ser uma estratégia eficiente para o enfrentamento do sofrimento emocional e objetivar uma melhor condução do atendimento. ${ }^{8}$

No que se refere a atuação dos enfermeiros, percebe-se um despreparo dos mesmos para lidarem com esse tipo de caso, o que pode resultar em encaminhamento da vítima a outro serviço e/ou na subnotificação dos casos, conforme observa-se:

É bem complexo, mas necessário. Ainda que a gente esteja em fase de aperfeiçoamento tanto da equipe quanto da mentalidade das mulheres que sofrem esse tipo de abuso. (E1)

É uma sensação de constrangimento, mas também nos sentimos importante por oferecer apoio em um momento tão difícil. (E3)

É difícil. A gente tem que ter muito tempo para essa paciente e a gente não consegue sentir a dor do paciente e menosprezar a dor dela. Resumindo, a gente precisa estar mais preparada para esse tipo de atendimento. (E4)

Vou ser bem sincera, esse tipo de atendimento não faz o meu gênero. Eu prefiro fazer outra coisa e agradeço muito a Deus não ser o meu dia-a-dia. Isso é muito bom para mim. (E5)

É um atendimento que você tem que estar preparado, pois a pessoa nesse meio pode reagir bem aos conselhos e todo o trabalho da enfermagem, mas ela também pode vir a ter outros problemas como: depressão e outras patologias geradas pelo problema e aí tem que se trabalhar com to- das as vias, pois pode até acontecer um suicídio por conta disso, por isso temos que promover o apoio da família. (E6)

Não me sinto totalmente segura, pois a própria vítima as vezes não quer denunciar. Só está ali para desabafar e me sinto com impotência. (E7)

A falta de conhecimento acerca da temática e a fragilidade em realizar escuta qualificada dos enfermeiros é decorrente, muitas vezes, devido ao desconhecimento acerca do impacto negativo causado na vítima de violência sexual, ${ }^{9}$ fazendo com que o profissional direcione o manejo da situação apenas para o modelo biomédico, deixando de lado uma atenção integral. ${ }^{6}$

Assim, torna-se necessário uma assistência de enfermagem que considere a subjetividade de cada mulher, ofertando um ambiente com privacidade, livre de preconceitos e de forma integral. Mediante essa realidade, o vínculo entre o profissional e a mulher vítima de violência sexual torna-se essencial para enfrentamento da violência e para o estabelecimento da relação de confiança, respeito e ética de modo a possibilitar a aproximação da vítima para continuidade da assistência. ${ }^{10}$ Além disso, a assistência deve ser voltada também para a saúde psicológica da mulher a partir de equipes disponíveis no território e/ ou na rede de atenção à saúde, devido aos impactos negativos, como a depressão e o isolamento. ${ }^{2}$

Identificou-se ainda nos depoimentos dos profissionais as dificuldades presentes no dia a dia para o atendimento das mulheres vítimas de violência:

A parte em si de saúde da família eu gosto muito. É minha paixão, pois a gente tenta lidar com a prevenção e não com a doença em si. O caos que está instalado na saúde hoje nos impede muitas vezes de fazer o que tem que ser feito. Essa semana eu tive um caso de uma 
gestante que depois da terceira consulta ela teve coragem de falar que a gravidez foi por estupro. Ela não tem o desejo de tirar, mas parece que a ficha não caiu ainda e eu olhar para essa gestante e sentir vontade de chorar porque já tinha mais dez pacientes na fila me esperando e você não ter o tempo que essa gestante necessita, nem para conversar, nem para ver a parte emocional, nem para conforta-la, não é fácil e tem que gostar mesmo. (E2)

Diante disso, o cuidado de enfermagem torna-se importante frente aos casos de violência sexual, pois compreende o processo de humanização e na criação de vínculo entre profissional e paciente com intuito de promover a resolução do problema em questão. ${ }^{11}$ Entretanto, uma das principais dificuldades encontradas nos serviços de saúde é a identificação dos casos de violência sexual devido à complexidade da sua abordagem, pois o silêncio tanto da vítima, como dos profissionais, acaba mascarando esta grave situação. ${ }^{2}$ Nesse sentido, a abordagem da vítima deve acontecer através de questionamentos indiretos, pois dessa forma há o estímulo das mesmas a verbalizarem sobre a situação de violência sofrida para continuidade e/ou início da assistência. ${ }^{6}$

Além disso, a ampliação de práticas educativas à população sobre a temática, bem como o desenvolvimento de ações de educação permanente voltada aos profissionais de saúde, em especial aos enfermeiros, sobre as situações que envolvem a violência contra a mulher e o fortalecimento da rede intersetorial e de apoio disponível no território podem ser estratégias para o enfrentamento da violência sexual. ${ }^{2,12}$

Portanto, para romper com a dificuldade em assistir de forma integral às muIheres vítimas de violência sexual, torna-se necessário a realização de momentos de reflexão e debate entre os profissionais nos serviços de saúde de modo a qualificar a atenção à saúde e garantir um adequado enfrentamento da violência sexual no território das equipes da atenção primária.13-14

\section{CONCLUSÃO}

O sentimento de empatia está presente nos enfermeiros que atendem às mulheres vítimas de violência sexual de forma que estes se sensibilizam com o fato. Identificou-se ainda como fatores limitantes o sentimento de frustação, a falta de conhecimento dos profissionais e a dificuldade de identificação dos casos devido à complexidade da sua abordagem, fato que pode levar a subnotificação dos casos.

Mediante essas limitações, torna-se necessário a abordagem através de questionamentos indiretos para estimular a verbalização do episódio de violência vivenciado, assim como a educação permanente dos enfermeiros com o intuito de aprofundar o conhecimento de modo a promover a qualificação da equipe para o enfrentamento da violência sexual contra às mulheres.

Assim, no que se refere às limitações do estudo acredita-se que esteja relacionada a realização da pesquisa em uma única UBS, uma vez que a ampliação para outras unidades de saúde poderia propiciar uma análise ampliada.

\section{Referências}

1. Sehnem GD, Lopes EB, Tier CG, Ribeiro AC, Maciel VQS, Castilhos L. Violence against women: nurse practice in primary health care. Rev Enferm UFSM. 2019;9(e61):1-19. Disponível em: https://periodicos.ufsm.br/reufsm/article/ view/35061/pdf

2. Silva NNF, Leal SMC, Trentin D, Vargas MAO, Vargas CP, Vieira LB. Atuação dos enfermeiros da atenção básica a mulheres em situação de violência. Enferm Foco (Brasilia). 2017;8(3)70-74. Disponível em: http://revista.cofen.gov.br/index.php/ enfermagem/article/view/1290

3. Sobrinho NC, Kasmirsck C, Soares JSSF, Pinhero MS, Fioravanti Junior GA. Violence against women: how nursing students perceive it. Rev J Nurs Health. 2019;9(1):e199102. Disponivel: https://periodicos.ufpel.edu.br/ojs2/index.php/ enfermagem/article/view/13222

4. Albuquerque Netto LA, Pereira ER, Tavares JMAB, Ferreira DC, Broca PV. Atuação da enfermagem na conservação da saúde de mulheres em situação de violência. REME Rev Min Enferm. 2018;22:e-1149. Disponível em: http://www.reme.org.br/ artigo/detalhes $/ 1292$

5. Minayo MCS. 0 desafio do conhecimento. 14 ed. São Paulo: Hucitec; 2014. 6. Zuchi CZ, Silva EB, Costa MC, Arboit J, Fontana DGR, Honnef F et al. Violência contra as mulheres: concepções de profissionais da estratégia saúde da família acerca da escuta. REME Rev Min Enferm. 2018;22:e1085. Disponível em: http:/l www.reme.org.br/artigo/detalhes/1223

7. Trigueiro TH, Silva MH, Oliveira DM, Jesus MCP, Merighi MAB. Non-adherence to outpatient follow-up by women who experienced sexual violence. Texto \& Contexto Enferm. 2018;27(1):e6490015. Disponível em: http://www.scielo.br/scielo. php?pid=S01047072018000100318\&script=sci_abstract\&tlng=pt

8. Vieira EM, Hasse M. Percepção dos profissionais de uma rede intersetorial sobre 0 atendimento a mulheres em situação de violência. Interface Comum Saúde Educ. 2017;21(60):51-62. Disponivel em: https://www.scielosp.org/article/ icse/2017.v21n60/52-62/

9. Batista VC, Back IR, Monteschio LVC, Arruda DC, Rickli HC, Grespan LR et al. Perfil das notificações sobre violência sexual. Rev Enferm UFPE On line. 2018;12(5):1372-80. Disponível em: https://periodicos.ufpe.br/revistas/revistaenfermagem/article/view/234546/29057

10. Heisler ED, Silva EB, Costa MC, Arboit J, Honnef F, Marques KA. Mulheres em situação de violência: (re)pensando a escuta, vínculo e visita. Rev Enferm UFPE On line. 2018;12(1):265-72. Disponível em: https://periodicos.ufpe.br/revistas/revistaenfermagem/article/view/230504/26102

11. Fornari LF, Sakata-So KN, Egry EY, Fonseca RMGS. Gender and generation perspectives in the narratives of sexually abused women in childhood. Rev Latinoam Enferm. (Online). 2018;26: e3078. Disponível em: https://www.revistas.usp.br/rlae/ article/view/156323

12. Costa L, Lordes RG, Fraga D, Santana NMT, Bubach S, Leite FMC. Estratégias de enfrentamento adotadas por mulheres vítimas de violência. Rev Enferm UERJ. 2018;26:e19334. Disponivel em: https://www.e-publicacoes.uerj.br/index.php/enfermagemuerj/article/view/19334

13. Silva CD, Gomes VLO. Violência contra a mulher: dimensões representacionais de discentes de enfermagem. Rev Enferm Centr-Oeste Min. 2018;8:e2528. Disponível em: http://www.seer.ufsj.edu.br/index.php/recom/article/view/2528 14. Machado MES, Rodrigues LSA, Fernandes ETBS, Silva JM, Silva DO, Oliveira JF. Perception of health professionals about violence against women: a descriptive stude. Rev Online Braz J Nurs. (Online). 2017;16(1):209-217. Disponivel em: http:// www.objnursing.uff.br/index.php/nursing/article/view/5596 